УДК 616.891:616.895.8:616.89-008.441.13:616-89-008.441.33:577.171

Для цитирования: Никитина В.Б., Лобачева О.А., Ветлугина Т.П., Аксенов М.М., Лебедева В.Ф. Нейроиммуноэндокринные нарушения при психических расстройствах и болезнях зависимости. Сибирский вестник психиатрии и наркологии. 2018; 2 (99): 45-55. https://doi.org/10.26617/1810-3111-2018-2(99)-45-55

\title{
Нейроиммуноэндокринные нарушения при психических расстройствах и болезнях зависимости
}

\section{Никитина В.Б., Лобачева О.А., Ветлугина Т.П., Аксенов М.М., Лебедева В.Ф.}

Научно-исследовательский институт психического здоровья, Томский национальный исследовательский медицинский изентр Российской академии наук (НИИ психического здоровья Томский НИМЦ) Россия, 634014, Томск, ул. Алеутская, 4

\section{PЕЗЮМЕ}

Одной из задач фундаментальных исследований в рамках научной платформы «Пихиатрия и зависимости» является изучение патогенетических механизмов психических расстройств и зависимостей с использованием комплексного клиникобиологического подхода. Цель - исследовать участие иммунной и эндокринной систем в клинико-динамических механизмах психических расстройств и болезней зависимости. Материал и методы - проведено комплексное клинико-иммуноэндокринное обследование 149 пациентов с непсихотическими психическими расстройствами, 65 больных шизофренией, 136 больных наркоманией и 18 мужчин, страдающих алкогольной зависимостью. Проведено фенотипирование иммунокомпетентных клеток по кластерам дифференцировки методом проточной цитометрии; определение концентраций сывороточных иммуноглобулинов классов M, G, А и уровня гормонов методом ИФА; определение концентрации цитокинов на мультиплексном анализаторе MAGPIX по технологии LuminexxMAP (USA); определение фагоцитарной активности нейтрофилов в тесте с меламинформальдегидным латексом. Результаты - получены данные, свидетельствующие об участии иммуноэндокринной системы в формировании психопатологических расстройств и их полиморфизма при непсихотических психических расстройствах с преобладанием тревожных и депрессивных симптомов. На основе иммунологического подхода разработаны способы прогнозирования затяжного течения невротических, связанных со стрессом и соматоформных расстройств. Отклонения в системе нейроиммуноэндокринной регуляции являются единым патогенетическим механизмом развития эндогенных расстройств. Получены новые данные об особенностях действия атипичного нейролептика рисперидона в процессе терапии на основные параметры иммунитета больных шизофренией в зависимости от наличия или отсутствия медикаментозной гиперпролактинемии. Установлена дизрегуляция параметров иммуноэндокринной системы при болезнях зависимости на всех исследуемых этапах терапии синдрома отмены, что свидетельствует о неустойчивости достигнутой терапевтической ремиссии, необходимости проведения дальнейших реабилитационных мероприятий, разработки подходов к новым алгоритмам лечения и реабилитации больных с целью стабилизации ремиссий и профилактики ранних рецидивов.

Ключевые слова: клиническая психонейроиммунология, иммунитет, цитокины, гормоны, непсихотические психические расстройства, шизофрения, алкоголизм, наркомания.

\section{ВВЕДЕНИЕ}

Одной из задач фундаментальных исследований в рамках научной платформы «Психиатрия и зависимости» является изучение патогенетических механизмов психических расстройств и зависимостей с использованием комплексного клинико-биологического подхода. В последние годы происходит активный рост числа больных непсихотическими психическими расстройствами, которые выделены в отдельную группу. Непсихотические психические расстройства нарушают нормальную деятельность только избирательных сфер человеческой психики и не вызывают серьезных отклонений в поведении личности, но способны ощутимо ухудшить качество жизни пациента. К факторам, вызывающим данные расстройства, относятся ускорение ритма жизни и многократно увеличивающиеся информационные нагрузки, стрессы, межличностные конфликты, длительное интеллектуальное и эмоциональное перенапряжение [1, 2, 3]. Важную роль в формировании проявлений непсихотических психических расстройств играют индивидуальная предрасположенность, общие неспецифические реакции организма на действие психотравмирующих факторов, в том числе и иммунная реактивность $[4,5,6]$.
К настоящему времени накоплен большой объем данных о роли нарушений нервной, иммунной и эндокринной систем в патогенетических механизмах шизофрении, существовании клинико-биологических, в том числе клинико-иммунологических стереотипов развития болезни $[7,8,9,10]$.

Экспериментальные и клинические данные указывают на нарушения при психических расстройствах и болезнях зависимости функционирования нейромедиаторных систем мозга $[11,12,13]$ и нейроиммунного взаимодействия, изучение которых осуществляется в рамках клинической психонейроиммунологии, постулирующей медиаторную, peцепторную, антигенную общность мозга и иммунной системы [14, 15, 16, 17, 18, 19].

Основными системами, реализующими стрессовые перестройки организма, являются гипоталамогипофизарно-надпочечниковая, гипоталамо-гипофизарно-тиреоидная и симпатоадреналовая системы, находящиеся под контролем высших отделов мозга и гипоталамуса, интенсивное функционирование которых сопровождается выбросом гормонов стресca $[20,21,22,23]$.

Анализ накопленных данных свидетельствует о том, что зависимость от психоактивных веществ 
(ПАВ) сопровождается перестройкой нейромедиаторных, нейроэндокринных, биохимических и иммунологических процессов организма [24, 25, 26, 27]. Важную роль в регуляции основных функций организма, связанных с поддержанием гомеостаза, выполняют цитокины. Показано, что длительное употребление алкоголя приводит к каскаду воспалительных реакций с ростом продукции цитокинов клетками Купфера, периферическими лимфоцитами, а также активированной микроглией [28, 29, 30].

Цель - исследовать участие иммунной и эндокринной систем в клинико-динамических механизмах психических расстройств и болезней зависимости.

\section{МАТЕРИАЛ И МЕТОДЫ}

Нами проведено комплексное клиникоиммуноэндокринное обследование 149 пациентов (27 мужчин и 122 женщин) с непсихотическими психическими расстройствами, 65 больных шизофренией (26 мужчин и 39 женщин), 136 больных наркоманией, которые инъекционно принимали экстракт опия, и 18 мужчин, страдающих алкогольной зависимостью. Согласно МКБ-10 группу обследованных с непсихотическими психическими расстройствами составили пациенты с расстройством адаптации (F43), паническим (F41), соматоформными (F45) и органическими эмоционально лабильными (астеническими) расстройствами (F06), в клинической картине которых преобладали тревожно-депрессивные проявления. В группу больных шизофренией вошли 46 пациентов (F20.01, F20.02, F20.05), получавших рисперидон, и 19 пациентов (F20.01, F20.02), получавших кветиапин. Все больные получали препараты не менее 6 месяцев перед поступлением в стационар в качестве базисной противорецидивной терапии. У наркологических больных диагностировали «Психические и поведенческие расстройства вследствие употребления психоактивных веществ» - синдром зависимости (F11.21) и синдром отмены (F.11.30). Все пациенты проходили курс стационарного лечения в психиатрических отделениях клиники НИИ психического здоровья Томского НИМЦ. Контрольную группу при биологических исследованиях составили 76 практически здоровых людей.

Долабораторную диагностику клинических синдромов вторичной иммунной недостаточности (ВИН) осуществляли с помощью «Карты диагностики иммунной недостаточности при иммуноэпидемиологических исследованиях взрослого населения» с выделением инфекционного, аллергического и аутоиммунного синдромов. В качестве материала для биологических исследований была использована венозная кровь. Забор крови осуществляли из локтевой вены утром натощак с использованием стерильной системы однократного применения Vacutainer («Becton Dickinson and Company», USA): для фенотипирования иммунокомпетентных клеток - в пробирки с антикоагулянтом ЭДТА; для получения сыворотки крови - в пробирки с активатором свертывания крови; для определения фагоцитарной активности лей- коцитов - в пробирки с антикоагулянтом гепарином.

Лабораторные методы включали:

- фенотипирование поверхностных рецепторов иммунокомпетентных клеток осуществляли на проточном цитометре системы FACS Calibur (Becton Dickinson, USA) с использованием реагентов данной фирмы по кластерам дифференцировки (CD): $\mathrm{CD}^{+} \mathrm{CD} 19^{-}$(зрелые Т-лимфоциты), $\mathrm{CD}^{+} \mathrm{CD}^{+}$(Tхелперы/индукторы), $\mathrm{CD}^{+} \mathrm{CD}^{+}$(цитотоксические Т-лимфоциты), $\mathrm{CD}^{-} \mathrm{CD} 19^{+}$(В-лимфоциты), $\mathrm{CD}^{-}$ $\mathrm{CD}_{16}^{+} \mathrm{CD}^{+}{ }^{+}$(натуральные клетки-киллеры, NKклетки), $\mathrm{CD}^{+} \mathrm{CD} 16^{+} \mathrm{CD} 56^{+}$(Т-клетки-киллеры, TNKклетки), $\mathrm{CD}^{+} \mathrm{HLADR}^{+}$(клетки, экспрессирующие маркеры поздней активации), $\mathrm{CD}^{+} \mathrm{CD}^{+} 5^{+}$(клетки, экспрессирующие Fac-рецепторы готовности к апоптозу);

- определение гуморальных факторов иммунитета - концентраций сывороточных иммуноглобулинов классов M, G, А методом ИФА с использованием набора реагентов (ЗАО «Вектор-Бест», Новосибирск, Россия) и уровня циркулирующих иммунных комплексов (ЦИК) в сыворотке крови полиэтиленгликолевым методом;

- определение фагоцитарной активности полиморфно-ядерных нейтрофилов в тесте с меламинформальдегидным латексом;

- культивирование клеток цельной крови с использованием набора реагентов «Цитокин-СтимулБест» (ЗАО «Вектор-Бест»), основными компонентами которого являются стерильная среда DMEM с гентамицином и комплексный митоген, представляющий смесь лиофилизированных поликлональных активаторов;

- определение концентрации воспалительных и провоспалительных цитокинов на мультиплексном анализаторе MAGPIX по технологии LuminexxMAP (USA);

- определение гормонального спектра (концентраций кортизола, пролактина, тестостерона, тиреотропного гормона (ТТГ) и гормонов щитовидной железы: трийодтиронина $-\mathrm{T}_{3}$ и тироксина $-\mathrm{T}_{4}$ ) в сыворотке крови методом ИФА с использованием соответствующих наборов реагентов (ЗАО «ВекторБест»).

Статистический анализ полученных данных проводили с использованием пакетов STATISTICA версия 12.0 для Windows. Для сравнения исследуемых выборок по качественным показателям применяли методы $\chi^{2}$, $\varphi$-преобразования Фишера и точного критерия Фишера. Анализ количественных данных проводили сравнением независимых выборок с помощью U-критерия Манна-Уитни, для проверки равенства медиан нескольких выборок применяли Н-тест Краскела-Уолисса. Иммуноэндокринные связи оценивали методом ранговой корреляции Спирмена. Критический уровень значимости при проверке статистических гипотез в исследовании принимали равным 0,05. Описательная статистика представлена медианой (Me) и межквартильным интервалом (LQ - UQ). 


\section{РЕЗУЛЬТАТЫ И ОБСУЖДЕНИЕ}

Непсихотические психические расстройства. Анализ данных долабораторного исследования больных непсихотическими психическими расстройствами с тревожными и депрессивными проявлениями выявил клинические признаки вторичной иммунной недостаточности у $84,6 \%$ пациентов с ведущим инфекционным синдромом, в том числе с сочетанием инфекционного и аутоиммунного синдромов. У 76,5\% обследуемых лиц установлена соматическая отягощенность. Лидирующие позиции занимают сердечно-сосудистые заболевания $(56,4 \%)$, эндокринопатии $(48,2 \%)$, частые инфекционные и вирусные заболевания в анамнезе $(32,0 \%)$, аллергические реакции $(25,7 \%)$.

Далее проводилось лабораторное обследование пациентов с определением иммунологических параметров и показателей гормонального статуса. В качестве контрольных значений использовали данные иммунного и гормонального статусов 76 практически здоровых людей. Наиболее значимыми отклонениями иммунологических показателей от нормы у больных с тревожной и депрессивной симптоматикой явились снижение количества Т-хелперов/ индукторов $\mathrm{CD}^{+} \mathrm{CD}^{+}$-фенотипа $(\mathrm{p}=0,040668)$ и $\mathrm{T}$ киллеров - $\quad \mathrm{CD}^{+} \mathrm{CD} 16^{+} \mathrm{CD} 56^{+}$-фенотипа $(\mathrm{p}=0,008961)$; высокие значения количества Влимфоцитов - CD3- и CD19 ${ }^{+}$-фенотипа ( $\left.=0,049231\right)$, клеток с CD95-рецепторами апоптоза ( $\mathrm{p}=0,000001)$ и концентрации сывороточного иммуноглобулина класса $\mathrm{G}(\mathrm{p}=0,025088)$; установлено снижение показателей фагоцитарной активности нейтрофилов $(\mathrm{p}=0,000070)$ (табл. 1).

Т а б ли ц а 1

\begin{tabular}{|c|c|c|c|}
\hline \multicolumn{4}{|c|}{ Иммунологические показатели больных с непсихотическими психическими расстройствами и здоровых лиц } \\
\hline \multirow[t]{2}{*}{ Показатель иммунитета } & \multicolumn{2}{|c|}{ Медиана (LQ - UQ) } & \multirow[t]{2}{*}{ Достоверность различий (p) } \\
\hline & Пациенты (n=149) & Здоровые лица (n=76) & \\
\hline Лейкоциты, $10^{9} /$ л & $6,0(4,9-7,3)$ & $6,5(5,7-7,4)$ & 0,026489 \\
\hline Лимфоциты, \% & $37(30-42)$ & $37(31-40)$ & 0,818498 \\
\hline $\mathrm{CD}^{+} \mathrm{CD}^{-} 9^{-}, \%$ & $75(70-79)$ & $76(69-80)$ & 0,486386 \\
\hline $\mathrm{CD}^{+}{ }^{+} \mathrm{CD} 4^{+}, \%$ & $47(40-52)$ & $48(43-55)$ & 0,040668 \\
\hline $\mathrm{CD}^{+} \mathrm{CD}^{+}, \%$ & $26(21-31)$ & $25(20-30)$ & 0,352101 \\
\hline $\mathrm{CD}^{-}-\mathrm{CD} 19^{+}, \%$ & $12(9-14)$ & $10(7-14)$ & 0,049231 \\
\hline $\mathrm{CD}^{+} \mathrm{HLADR}^{+}, \%$ & $16(12-20)$ & $18(12-26)$ & 0,120647 \\
\hline $\mathrm{CD}^{-}{ }^{-\mathrm{CD}} 16^{+} \mathrm{CD} 56^{+}, \%$ & $12(9-15)$ & $12(8-15)$ & 0,873562 \\
\hline $\mathrm{CD}^{+}{ }^{+} \mathrm{CD} 16^{+} \mathrm{CD}^{2} 6^{+}, \%$ & $3(2-5)$ & $4(2-7)$ & 0,008961 \\
\hline $\mathrm{CD}^{+} \mathrm{CD} 95^{+}, \%$ & $11(7-18)$ & $5(4-7)$ & 0,000001 \\
\hline IgM, Г/л & $1,73(1,16-2,30)$ & $2,08(1,54-2,42)$ & 0,067150 \\
\hline $\mathrm{IgG}$, Г/л & $16,80(13,04-22,12)$ & $15,27(12,48-18,29)$ & 0,025088 \\
\hline $\operatorname{IgA}$, Г/л & $1,64(1,16-2,38)$ & $1,74(1,33-2,17)$ & 0,780871 \\
\hline ЦИК, усл. ед. & $84(52-98)$ & $67(48-98)$ & 0,600064 \\
\hline ФИ,\% & $62(54-70)$ & $54(48-58)$ & 0,000070 \\
\hline
\end{tabular}

Исследование гормонального статуса отражено в таблице 2. В общей группе пациентов установлено значительное повышение концентрации кортизола $(\mathrm{p}=0,000001)$, тиреотропного гормона - ТТГ
( $p=0,000002)$ и пролактина, причем как у мужчин $(\mathrm{p}=0,000070)$, так и у женщин $(\mathrm{p}=0,000086)$.

Таблица 2

Показатели гормонального статуса больных с непсихотическими психическими расстройствами и здоровых лиц

\begin{tabular}{|c|c|c|c|c|}
\hline \multicolumn{2}{|c|}{ Показатель } & \multicolumn{2}{|c|}{ Медиана (LQ - UQ) } & \multirow[t]{2}{*}{ Достоверность различий (p) } \\
\hline & & Пациенты (n=149) & Здоровые лица (n=44) & \\
\hline \multicolumn{2}{|l|}{ Кортизол, нмоль/л } & $592,1(399,5-759,2)$ & $367,8(307,7-493,8)$ & 0,000001 \\
\hline \multirow{2}{*}{ Тестостерон, нмоль/л } & Мужчины & $23,0(17,3-27,0)$ & $19,4(15,1-22,0)$ & 0,200976 \\
\hline & Женщины & $2,8(0,3-5,1)$ & $1,9(1,4-2,6)$ & 0,402960 \\
\hline \multirow[t]{2}{*}{ Пролактин, мМЕ/л } & Мужчины & $485,7(271,7-775,7)$ & $267,5(168,4-362,0)$ & 0,000070 \\
\hline & Женщины & $490,9(169,3-491,0)$ & $296,0(187,0-399,2)$ & 0,000086 \\
\hline \multicolumn{2}{|l|}{ ТТГ, мкМЕ/мЛ } & $1,53(0,84-2,35)$ & $2,37(1,69-3,15)$ & 0,000002 \\
\hline \multicolumn{2}{|l|}{ Т3 своб, пмоль/л } & $3,04(2,13-5,61)$ & $1,50(1,36-1,75)$ & 0,000001 \\
\hline \multicolumn{2}{|l|}{ Т4 своб, пмоль/л } & $13,33(10,74-14,88)$ & $24,0(19,0-29)$ & 0,000228 \\
\hline
\end{tabular}

Кортизол вырабатывается в экстренных и/или стрессовых ситуациях и, бесспорно, выступает одним из самых главных гормонов, но при хроническом стрессе, когда его продукция превышает уровень нормы, он становится патогенным фактором $[31,32]$. Пролактин активно участвует в формировании адаптивных реакций, возникающих при действии на организм различных экстремальных факторов, оказывает иммунорегулирующий эффект, регулирует психические функции, влияет на поведенческие реакции $[33,34,35]$. Стрессиндуцированный выброс пролактина - не просто побочный эффект адренергической активации ЦНС, но и фактор сглаживания гомеостатических нарушений, играющий роль в поведенческой адаптации к неблагоприятным условиям окружающей среды.

В нейроанатомическом плане стресс традиционно связывают с нарушением состояния лимбической 
системы мозга [31]. Именно в структурах лимбикодиэнцефальной системы (гипоталамус, гиппокамп, амигдала), которая входит в состав нервной регуляции функций иммунологической защиты, и расположены эмоциональные зоны [36, 37, 38]. Чрезмерная гиперактивность эмоциональных зон лимбической системы при стрессе дезорганизует деятельность регуляторного аппарата, нарушает нейроиммунную регуляцию, индуцирует патологию функции иммунитета [15]. Это приводит к формированию вторичной иммунной недостаточности, иммунодефицитам, снижению сопротивляемости к инфекциям, развитию хронических и рецидивирующих процессов, что осложняет клиническую картину непсихотических психических расстройств, способствует их затяжному течению $[5,39]$.

В наших исследованиях получены новые данные о роли нейроиммуноэндокринной регуляции в клинико-динамических механизмах формирования непсихотических психических расстройств. На основе комплекса иммунологических, эндокринных параметров у пациентов на ранних стадиях расстройства приспособительных реакций выделены критерии прогноза риска формирования панического расстройства и стойкого изменения личности, которые поддержаны патентами РФ [40, 41]. На основе иммунологического подхода разработан способ прогнозирования затяжного течения соматоформных расстройств [42].

Шизофрения. Основным способом лечения шизофрении является длительная антипсихотическая терапия, которая улучшает долгосрочный прогноз заболевания и способствует его переходу в состояние ремиссии [43, 44, 45]. Кроме основного антипсихотического действия данные препараты при их длительном применении оказывают дезадаптирую- щее влияние на организм, которое сопровождается различными побочными эффектами и явлениями, в том числе медикаментозной гиперпролактинемией (МГ), снижающими эффективность терапии [46, 47 , 48, 49, 50].

Изучены иммунологические факторы, ассоциированные с риском развития МГ 46 больных шизофренией, получавших рисперидон не менее 6 месяцев перед поступлением в стационар в качестве базисной противорецидивной терапии. Из исследования исключались лица с эндокринными и онкологическими заболеваниями, сопровождающимися гиперпролактинемией. Исследуемые пациенты были распределены на две группы: в группу с МГ вошло 36 человек с повышенным уровнем пролактина (выше $525 \mathrm{MME} / л$ у женщин и 420 мМЕ/л - у мужчин), в группу без МГ - 10 человек с концентрацией пролактина крови на уровне значений региональной нормы.

В результате проведенного исследования установлено, что клиническая симптоматика шизофрении на фоне лечения рисперидоном сопровождается иммунным дисбалансом со значимым отклонением ряда иммунологических параметров от значений региональной иммунологической нормы. Получены новые данные об особенностях действия атипичного нейролептика рисперидона в процессе терапии на основные параметры иммунитета больных шизофренией в зависимости от наличия или отсутствия медикаментозной гиперпролактинемии (табл. 3): у пациентов с МГ по сравнению с пациентами без МГ выявлены более низкие значения относительного количества зрелых Т-лимфоцитов $\mathrm{CD}^{+} \mathrm{CD} 19^{-}$ $(\mathrm{p}=0,028)$, В-лимфоцитов $\mathrm{CD}^{-} \mathrm{CD}^{+} 9^{+}(\mathrm{p}=0,014)$ и хелперов/индукторов $\mathrm{CD}^{+} \mathrm{CD}^{+}$, которое не достигало уровня достоверности $(\mathrm{p}=0,083)$.

Показатели иммунитета в группах больных шизофренией с медикаментозной
гиперпролактинемией и без медикаментозной гиперпролактинемии

П р и м е ч а н ие. p- Достоверность различий между группами; LQ - нижний квартиль, UQ - верхний квартиль.

Пролактин, как известно, принимает участие в формировании адаптивных реакций, возникающих при действии на организм различных экстремальных факторов, влияет на психические функции и поведенческие реакции, оказывает иммунорегулирующий эффект [33, 34, 35]. Более выраженные им- мунологические отклонения, выявленные в группе пациентов с медикаментозной гиперпролактинемией, могут быть связаны с особенностями нейроиммуноэндокринной регуляции в приспособительных механизмах больных шизофренией в процессе клинической динамики и терапии. 
Было проведено обследование 19 пациентов (F20.01, F20.02, в возрасте от 20 до 45 лет, 9 мужчин и 10 женщин), которые перед поступлением в стационар получали кветиапин не менее 6 месяцев в качестве базисной противорецидивной терапии. Установлено, что острый период шизофрении после длительного поддерживающего лечения кветиапином сопровождается иммуногормональным дисбалансом, характеризующимся клеточным иммунодефицитом со снижением количества зрелых Тлимфоцитов $\mathrm{CD}^{+} \mathrm{CD}^{-} \quad(\mathrm{p}=0,040) \quad$ и $\quad \mathrm{T}$ -

хелперов/индукторов $\mathrm{CD}^{+} \mathrm{CD}^{+}(\mathrm{p}=0,007)$, а также повышением численности клеток, экспрессирующих маркеры поздней активации $\mathrm{CD}^{+} \mathrm{HLADR}^{+}(\mathrm{p}=0,004)$ и натуральных клеток-киллеров $\mathrm{CD}^{+} \mathrm{CD} 16^{+} \mathrm{CD} 56^{+}$ ( $\mathrm{p}=0,000002)$ по сравнению со здоровыми лицами.

В результате проведенного исследования нами выявлено повышение уровня ТТГ, нарушение функции щитовидной железы со снижением выработки тиреоидных гормонов (табл. 4), а также длительное повышение уровня кортизола в крови.

Т а бл и ц а 4 Динамика уровня гормонов в группе больных шизофренией, длительно принимающих кветиапин

\begin{tabular}{|c|c|c|c|c|}
\hline \multirow{2}{*}{ Показатель } & \multirow{2}{*}{ Здоровые лица (n=76) } & \multicolumn{2}{|c|}{ Больные шизофренией, Me (LQ - UQ) } & \multirow[t]{2}{*}{ Достоверность различий (р) } \\
\hline & & 1-я точка $(\mathrm{n}=19)$ & 2-я точка $(n=14)$ & \\
\hline Кортизол, нмоль/л & $460,48(359,8-538,10)$ & $677,80(574,90-888,80)$ & $705,50(524,20-904,90)$ & $\mathrm{p}_{\mathrm{k} 1}=0,0001, \mathrm{p}_{\mathrm{k} 2}=0,0001$ \\
\hline Пролактин, мкМЕ/мл & $245,06(131,59-420,35)$ & $198,20(72,30-447,30)$ & $353,50(128,50-835,80)$ & $\mathrm{p}_{\mathrm{k1}}=0,749, \mathrm{p}_{\mathrm{k} 2}=0,251$ \\
\hline ТТГ, мкМЕ/мл & $1,28(0,74-1,68)$ & $2,50(1,60-3,60)$ & $2,60(1,60-5,00)$ & $\mathrm{p}_{\mathrm{k} 1}=0,008, \mathrm{p}_{\mathrm{k} 2}=0,0001$ \\
\hline Т4, пмоль/л & $18,40(14,69-22,73)$ & $11,20(9,20-13,0)$ & $9,9(9,30-12,10)$ & $\mathrm{p}_{\mathrm{k} 1}=0,0003, \mathrm{p}_{\mathrm{k} 2}=0,0001$ \\
\hline Т3, пмоль/л & $5,16(4,40-5,39)$ & $1,45(1,20-2,80)$ & $1,70(1,50-3,30)$ & $\mathrm{p}_{\mathrm{k} 1}=0,0001, \mathrm{p}_{\mathrm{k} 2}=0,0001$ \\
\hline $\mathrm{T} 3 / \mathrm{T} 4$ & $0,24(0,16-0,35)$ & $0,17(0,10-0,22)$ & $0,18(0,17-0,22)$ & $\mathrm{p}_{\mathrm{k} 1}=0,005, \mathrm{p}_{\mathrm{k} 2}=0,021$ \\
\hline
\end{tabular}

П р и м е ч а н и е. $p_{\kappa}-$ Уровень значимости по отношению к контролю.

Проведен анализ сопряженности между иммунологическими и эндокринными параметрами в группе обследованных больных шизофренией в 1-й точке исследования. Установлены статистически значимые ассоциативные связи между $\mathrm{CD}^{+} \mathrm{CD}^{+}-$ лимфоцитами и пролактином $\left(\mathrm{r}_{\mathrm{s}}=-0,60, \mathrm{p}=0,088\right)$, ЦИК и кортизолом $\left(\mathrm{r}_{\mathrm{s}}=0,82, \mathrm{p}=0,007\right)$. Между параметрами клеточного иммунитета и уровнем кортизола не выявлено значимых взаимосвязей. Вместе с тем усиливается вовлеченность в иммуноэндокринную интеграцию тиреотропного гормона (ТТГ): $\mathrm{CD}^{+} \mathrm{CD}^{+} \quad$ и $\mathrm{TT} ~\left(\mathrm{r}_{\mathrm{s}=}-0,67, \quad \mathrm{p}=0,035\right)$, $\mathrm{CD}^{+} \mathrm{CD}^{+} 6^{+} \mathrm{CD}^{+} 6^{+}$и ТТГ $\left(\mathrm{r}_{\mathrm{s}}=-0,65, \mathrm{p}=0,041\right), \mathrm{CD}^{+} 5^{+}$ и ТТГ $\left(\mathrm{r}_{\mathrm{s}}=0,74, \mathrm{p}=0,014\right), \quad \operatorname{IgA}$ и ТТГ $\left(\mathrm{r}_{\mathrm{s}}=-0,81\right.$, $\mathrm{p}=0,004)$ и тироксина $\left(\mathrm{T}_{4}\right): \mathrm{CD}^{+}{ }^{\mathrm{CD}} 16^{+} \mathrm{CD}^{+} 6^{+}$и $\mathrm{T}_{4}$ $\left(r_{s}=0,63, p=0,050\right), \mathrm{CD}^{-} \mathrm{CD} 19^{+}$и $\mathrm{T}_{4}\left(\mathrm{r}_{\mathrm{s}}=0,67, \mathrm{p}=0,035\right)$, $\mathrm{CD}^{+} 5^{+}$и $\mathrm{T}_{4}\left(\mathrm{r}_{\mathrm{s}}=-0,62, \mathrm{p}=0,046\right)$.

В процессе лечения в стационаре позитивная динамика психопатологической симптоматики сопровождалась позитивной динамикой зрелых Тлимфоцитов $\mathrm{CD}^{+} \mathrm{CD} 19$ и $\mathrm{T-хелперов/индукторов}$ $\mathrm{CD} 3{ }^{+} \mathrm{CD}^{+}$, уровень кортизола и тиреотропного гормона оставался высоким на фоне тенденции к повышению уровня пролактина.

Концепции этиопатогенеза шизофрении, в том числе модель предрасположенности к влиянию стрессов, предполагают в качестве предрасположенности к процессу генетическую уязвимость, влияние биологических факторов и/или факторов окружающей среды. Биологические эффекты стресса реализуются при участии гипоталамогипофизарно-надпочечниковой (ГГА) оси, регулирующей метаболизм стероидных гормонов [22, 23]. Тем самым при стресс-реакции функциональная дизрегуляция ГГА-системы запускает нарушения процессов саморегуляции и развитие клинических проявлений шизофрении [51].

В проведенном нами исследовании, как и в других исследованиях при шизофрении, авторы отме- чают гиперсекрецию кортизола, которое является одним из механизмов иммуносупрессии при шизофрении [7, 52] и приводит к различным метаболическим нарушениям [53, 54]. Тиреоидные гормоны играют очень важную роль в развитии головного мозга, повышают метаболическую активность и чувствительность практически всех тканей организма к циркулирующим в крови катехоламинам. В свою очередь катехоламины, помимо действия на тиреоциты, влияют на кровоток в щитовидной железе и изменяют обмен тиреоидных гормонов на периферии, что может сказываться на ее секреторной функции. [46].

Психические и поведенческие расстройства вследствие употребления психоактивных веществ. Исследование больных опийной наркоманией проводилось на следующих этапах: при поступлении в стационар (опийный абстинентный синдром OAC), на 5-7-е сутки терапии (переход в постабстинентное состояние - ПАС), на 25-28-й день лечения (становление терапевтической ремиссии - СТР). Установлено, что основной иммуноэндокринный паттерн на всех этапах терапии синдрома отмены характеризуется по сравнению с контролем количественным дефицитом субпопуляций Т-лимфоцитов $\mathrm{CD}^{+}, \mathrm{CD}^{+}, \mathrm{CD}^{+}$, а также активацией гуморальных факторов иммунитета (IgM, IgG, ЦИК) и высокой концентрацией кортизола. На этапе ОАС и ПАС эти изменения оказались наиболее выраженными. На 25-28-й день лечения отмечена позитивная динамика Т-лимфоцитов $\mathrm{CD}^{+}$и цитотоксических Тлимфоцитов $\left(\mathrm{CD}^{+}\right)$. В то время как хелперы/индукторы $\mathrm{CD}^{+}$оставались устойчиво сниженными, параметры гуморального иммунитета и концентрация кортизола были повышенными. Клинико-иммунологический анализ показал, что употребление высоких доз наркотика, длительный срок наркотизации связаны с большей выраженностью выявленных нарушений [55]. 
Участие цитокинов в патогенезе болезней зависимости обсуждается в литературе, как правило, на основе определения их концентрации в сыворотке крови, однако практически отсутствуют данные по исследованию продукции цитокинов мононуклеарами пациентов. Нами проведены исследования способности лимфоцитов зависимых от алкоголя пациентов к спонтанной продукции провоспалительных цитокинов.

Исследования проведены в двух точках: 1-я точка - на 3-4-й день поступления пациента в стацио-

нар, 2-я точка - на 12-14-й день стандартной терапии синдрома отмены и постабстинентного состояния.

Наше исследование выявило (табл. 5) повышение спонтанной продукции мононуклеарами больных алкоголизмом всего спектра определяемых цитокинов на этапах синдрома отмены. Наиболее высокие концентрации отмечены для IFN $\gamma$, IL-17A. Через 2 недели терапии концентрация цитокинов в супернатантах культуры клеток крови оставалась высокой.

Т а б ли ц а 5 Спонтанная продукция цитокинов мононуклеарами больных алкоголизмом в динамике обследования

\begin{tabular}{|c|c|c|c|}
\hline \multirow{2}{*}{$\begin{array}{c}\text { Концентрация цитокинов в супернатантах } \\
\text { культуры клетоккрови (пг/мл) }\end{array}$} & \multicolumn{2}{|c|}{ Медиана (LQ - UQ) } & \multirow[t]{2}{*}{ Достоверность различий (p) } \\
\hline & Пациенты (n=18) & Здоровые лица (n=26) & \\
\hline \multicolumn{4}{|c|}{ 1-я точка исследования } \\
\hline $\mathrm{IFN} \gamma$ & $7,66(6,78-8,56)$ & $0,13(0,060-2,68)$ & 0,0006 \\
\hline IL-17A & $8,66(8,38-9,03)$ & $1,19(0,10-8,28)$ & 0,00002 \\
\hline IL-1b & $4,06(3,73-4,56)$ & $3,85(0,500-8,072)$ & 0,046 \\
\hline IL-2 & $2,41(2,29-2,64)$ & $1,91(0,060-1,25)$ & 0,004 \\
\hline TNF $\alpha$ & $11,11(10,18-12,52)$ & $5,62(0,95-6,98)$ & 0,026 \\
\hline \multicolumn{4}{|c|}{ 2-я точка исследования } \\
\hline IFN $\gamma$ & $8,11(7,22-10,84)$ & $0,13(0,060-2,68)$ & 0,0007 \\
\hline IL-17A & $8,66(8,47-9,39)$ & $1,191(0,10-8,28)$ & 0,00001 \\
\hline IL-1b & $3,39(2,89-5,38)$ & $3,847(0,500-8,072)$ & 0,03 \\
\hline IL-2 & $2,53(2,41-2,53)$ & $1,914(0,060-1,25)$ & 0,006 \\
\hline TNF $\alpha$ & $12,21(8,47-12,39)$ & $5,62(0,950-6,98)$ & 0,01 \\
\hline
\end{tabular}

Известно, что спонтанная продукция цитокинов отражает текущее состояние мононуклеаров и их активацию различными факторами, которая произошла в организме in vivo [56]. Такими факторами могут быть модифицированные биомолекулы, антитела против модифицированных белковых аддуктов с продуктами метаболизма этанола и др. Значимый вклад в патогенез алкогольной зависимости вносит окислительный стресс [57]. Этанол, ацетальдегид и продукты окислительного стресса генерируют повышенное количество белков Toll-подобных peцепторов (TLRs), которые активируют микроглию и клетки Купфера с усилением продукции цитокинов и других воспалительных медиаторов, изменяют презентацию антигена и адаптивный иммунный ответ $[58,59,60]$.

Длительное чрезмерное потребление алкоголя является мощным стрессором, стимулирующим гипоталамо-гипофизарно-надпочечниковую ось и синтез глюкокортикоидов, вызывая стойкую дизрегуляцию систем вознаграждения мозга. Ранее нами было установлено повышение уровня кортизола и преобладание катаболических процессов метаболизма над анаболическими на всех исследуемых этапах синдрома отмены [61].

Большинство исследуемых факторов врожденного и адаптивного иммунитета у больных наркоманией и алкогольной зависимостью сохраняется на всех этапах синдрома отмены до конца срока наблюдения, что свидетельствует о неустойчивости достигнутой терапевтической ремиссии, высоком риске рецидива заболевания, необходимости разработки новых методов терапии с включением противовоспалительных и иммуномодулирующих средств.

\section{ЗАКЛЮЧЕНИЕ}

Проведенное комплексное иммунобиологическое исследование пациентов с непсихотическими психическими расстройствами с преобладанием тревожных и депрессивных симптомов свидетельствует об участии иммуноэндокринной системы в формировании психопатологических расстройств и их полиморфизма. На основе иммунологического подхода разработаны способы прогнозирования затяжного течения невротических, связанных со стрессом и соматоформных расстройств. Полученные данные демонстрируют, что отклонения в системе нейроиммуноэндокринной регуляции являются единым патогенетическим механизмом развития эндогенных расстройств. Результаты исследования могут быть использованы в практическом здравоохранении для выбора оптимального антипсихотика для конкретного пациента и позволят обосновать подходы к иммунокоррекции побочных эффектов применяющихся препаратов с целью оптимизации нейроиммунного взаимодействия и повышения адаптационных возможностей пациентов. Установлена дизрегуляция параметров иммуноэндокринной системы при болезнях зависимости на всех исследуемых этапах терапии синдрома отмены, что свидетельствует о неустойчивости достигнутой терапевтической ремиссии, необходимости проведения дальнейших реабилитационных мероприятий, разработки подходов к новым алгоритмам лечения и реабилитации больных с целью стабилизации ремиссий и профилактики ранних рецидивов.

\section{КОНФЛИКТ ИНТЕРЕСОВ}

Авторы заявляют об отсутствии конфликта интересов в связи с публикацией данной статьи. 


\section{ИСТОЧНИК ФИНАНСИРОВАНИЯ}

Авторы заявляют об отсутствии финансирования при проведении исследования.

\section{СООТВЕТСТВИЕ ПРИНЩИПАМ ЭТИКИ}

Исследование с участием людей проведено с соблюдением принципов информированного согласия Хельсинкской декларации Всемирной медицинской ассоциации и одобрено Локальным этическим комитетом при НИИ психического здоровья Томского НИМЦ (протокол № 53 от 01.10.2012 г.).

\section{ЛИТЕРАТУРА}

1. Аксенов М.М., Стоянова И.Я., Цыбульская Е.В., Костин А.К. Психологические особенности пациентов пожилого возраста с непсихотическими психическими расстройствами. Вестник Томского государственного педагогического университета. 2015; 3 (156): 58-63.

2. Бохан Н.А., Гычев А.В., Рахмазова Л.Д., Васильева Н.А. Распространенность непсихотических психических расстройств в Сибирском федеральном округе: взаимосвязь с региональными социально-экономическими трендами развития. Сочиальная и клиническая психиатрия. 2015; 25 (2): $78-82$.

3. Колмогорова В.В. Типология, социально-демографические и клинико-психологические характеристики при формировании непсихотических нервно-психических расстройств Научные исследования: от теории к практике. 2016; 4-1 (10): 83-86.

4. Секирина Т.П., Омельченко М.А., Румянцев А.О. Исследование продукции про- и противовоспалительных цитокинов при непсихотических расстройствах юношеского возраста. Психиатрия. 2015; 1 (65): 24-28.

5. Никитина В.Б. Роль иммунных механизмов в клинической динамике посттравматических стрессовых расстройств. $\mathrm{Cu}$ бирский вестник психиатрии и наркологии. 2009; 3 (54): 14 16.

6. Иванова С.А. Психоэмоциональный стресс и иммунитет (обзор). Сибирский вестник психиатрии и наркологии. 2000; 1: $31-37$.

7. Лобачева О.А. Сравнительная оценка иммуномодулирующих эффектов атипичных нейролептиков. Сибирский вестник психиатрии и наркологии. 2011; 1 (64): 100-102.

8. Ветлугина Т.П., Невидимова Т.И., Семке В.Я. Клиническая психонейроиммунология. В кн.: Актуальные проблемы нейроиммунопатологии: Руководство / под ред. Г.Н. Крыжановского, С.Н. Магаевой, С.Г. Морозова. М.: Изд-во Гениус Медиа, 2012; глава 7: 316-354.

9. Müller N., Wagner J.K., Krause D., Weidinger E., Wildenauer A., Obermeier M., Dehning S., Gruber R., Schwarz M.J. Impaired monocyte activation in schizophrenia. Psychiatry. 2012; 198 (3): 341-346. doi: 10.1016/j.psychres.2011.12.049

10. Girgis R.R., Kumar S.S., Brown A.S. The cytokine model of schizophrenia: emerging therapeutic strategies. Biol. Psychiatry. 2014; 75 (4): 292-299. doi: 10.1016/j.biopsych.2013.12.002

11. Muller N., Schwarz M. Schizophrenia as an inflammationmediated dysbalance of glutamatergic neurotransmission. $\mathrm{Neu}$ rotox Res. 2006; 10 (2):131-48.

12. Бохан Н.А., Иванова С.А., Левчук Л.А. Серотониновая система в модуляции депрессивного и аддиктивного поведения. Томск: Изд-во ТГУ, 2013: 102.

13. Volkow N.D., Koob G.F., McLellan A.T. Neurobiological Advances from the Brain Disease Model of Addiction. N. Engl. J. Med. 2016; 374 (4): 363-71. doi: 10.1056/NEJMra1511480

14. Девойно Л.В., Идова Г.В., Альперина Е.Л. Психонейроиммуномодуляция: поведение и иммунитет. Роль «нейромедиаторной установки мозга». Новосибирск: Наука, 2009: 168

15. Крыжановский Г.Н., Акмаев И.Г., Магаева С.В., Морозов С.Г. Нейроиммуноэндокринные взаимодействия в норме и патологии. М.: Медицинская книга, 2010: 288.

16. Маркова Е.В. Механизмы нейроиммунных взаимодействий в реализации поведенческих реакций. Красноярск: Научноинновационный центр, 2012: 236.
17. Ader R., Cohen N., Felten D. Psychoneuroimmunology: interactions between the nervous system and the immune system. Lancet. 1995; 345 (8942): 99-103.

18. Devoino L., Cheido M, Alperina E., Idova G. Evidence for a role of dopaminergic mechanisms in the immunostimulating effect of $\mu$ opioid receptor agonist DAGO. International Journal of Neuroscience. 2003; 113 (10): 1381-1394. doi:10.1080/00207450390231437

19. McGorry P., Keshavan M., Goldstone S., Amminger P., Allott K., Berk M., Lavoie S., Pantelis C., Yung A., Wood S., Hickie I. Biomarkers and clinical staging in psychiatry. World Psychiatry. 2014; 13 (13): 211-223.

20. Кубасов Р.В. Гормональные изменения в ответ на экстремальные факторы внешней среды. Вестник Российской академии медииинских наук. 2014; 9-10: 102-109.

21. Шушпанова Т.В., Новожеева Т.П., Мандель А.И., Бохан Н.А. Бензодиазепиновые рецепторы тромбоцитов и нейроактивные стероидные гормоны в крови человека - потенциальные мишени при алкогольной аддикции. Академический журнал Западной Сибири. 2014; 3 (52): 73-75.

22. Ranabir S., Reetu K. Stress and hormones. Indian J Endocrinol Metab. 2011; 1: 18-22. doi: 10.4103/2230-8210.77573

23. Babb J.A., Carini L.M., Spears S.L., Nephew B.C. Transgenerational effects of social stress on social behavior, corticosterone, oxytocin, and prolactin in rats. Horm Behav. 2014; 4: 386-393. doi: 10.1016/j.yhbeh.2014.03.005

24. Гамалея Н.Б. Нарушения функций иммунной системы при алкогольной и наркотической зависимости. В книге: Иванец Н.Н., Анохина И.П., Винникова М.А. (редакторы). Наркология. Национальное руководство. М.: Изд-во «ГЭОТАРМедиа»; 2008: 116-134.

25. Анохина И.П. Основные биологические механизмы зависимости от психоактивных веществ. Вопросы наркологии. 2013; 6: 40-59.

26. Chang M.C., Fan S.Z., Hsiao P.N., Cheng W.F., Sun W.Z. Influence of morphine on host immunity. Acta Anaesthesiol. Taiwan. 2011; 49 (3): 105-108. doi: 10.1016/j.aat.2011.08.003

27. Crews F.T., Vetreno R.P. Neuroimmune basis of alcoholic brain damage. Int Rev Neurobiol. 2014; 118: 315-57. doi: 10.1016/B978-0-12-801284-0.00010-5

28. Панченко Л.Ф., Пирожков С.В., Наумова Т.А., Теребилина Н.Н., Баронец В.Ю., Федоров И.Г., Тотолян Г.Г. Изменение профиля воспалительных и противовоспалительных цитокинов при развитии алкогольной болезни печени. Наркология. 2010; 4 (100): 86-77.

29. Afshar M., Richards S., Mann D., Cross A., Smith G.B., Netzer G., Kovacs E., Hasday J. Acute immunomodulatory effects of binge alcohol ingestion. Alcohol. 2015; 49 (1): 57-64. doi: 10.1016/j.alcohol.2014.10.002

30. Manzardo A.M., Poje A.B., Penick E.C., Butler M.G. Multiplex Immunoassay of Plasma Cytokine Levels in Men with Alcoholism and the Relationship to Psychiatric Assessments. Int J Mol Sci. 2016; 17 (4): 472. doi: 10.3390/ijms17040472

31. McEwen B.S. Physiology and neurobiology of stress and adaptation: central role of the brain. Physiol Rev. 2007; 3: 873-904. doi:10.1152/physrev.00041.2006

32. Charney D.S. Psychobiological mechanisms of resilience and vulnerability: implications for successful adaptation to extreme stress. Am. J. Psychiatry. 2004; 161 (2): 195-216. doi: 10.1176/appi.ajp.161.2.195.

33. Коломаченко В.І., Кривобок В.І., Фесенко В.С. Передопераційна та післяопераційна тривожність в ортопедичних пацієнтів: кореляція 3 біохімічними стрес-маркерами. Український вісник психоневрології. 2010; 2 (63): 52-56.

34. Lennartsson A.K., Jonsdottir I.H. Prolactin in response to acute psychosocial stress in healthy men and women. Psychoneuroendocrinology. 2011; $36 \quad$ (10): 1530-1539. doi: 10.1016/j.psyneuen.2011.04.007

35. Labad J., Stojanovic-Pérez A., Montalvo I., Solé M. Stress biomarkers as predictors of transition to psychosis in at-risk mental states: roles for cortisol, prolactin and albumin. $J$ Psychiatr Res. 2015; 60: 163-169. doi: 10.1016/j.jpsychires.2014.10.011

36. Heimer L., Van Hoesen G.W. The limbic lobe and its output channels: implications for emotional functions and adaptive behavior. Neurosci. Biobehav. Rev. 2006; 30 (2): 126-147. doi: 10.1016/j.neubiorev.2005.06.006 
37. Matarese G., Procaccini C., Menale C., Kim J.G., Kim J.D., Diano S., Diano N., De Rosa V., Dietrich M.O., Horvath T.L. Hunger-promoting hypothalamic neurons modulate effector and regulatory T-cell responses. Proc Natl Acad Sci USA. 2013; 110 (15): 6193-6198. doi: 10.1073/pnas.1210644110

38. Christensen R., Van Ameringen M., Hall G. Increased activity of frontal and limbic regions to emotional stimuli in children at-risk for anxiety disorders. Psychiatry Res. 2015; Jul 30; 233 (1): 917. doi: 10.1016/j.pscychresns.2015.04.004

39. Ветлугина Т.П., Невидимова Т.И., Никитина В.Б., Лобачева О.А., Бохан Н.А., Семке В.Я. Патогенетическое обоснование технологии иммунокоррекции при психических расстройствах и болезнях зависимости. Сибирский вестник психиатрии и наркологии. 2013; 1 (76): 7-12.

40. Патент 2644309 Российская Федерация. Способ прогнозирования риска формирования панического расстройства на ранней стадии заболевания / В.Б. Никитина, Т.В. Казенных, А.А. Иванова, Е.В. Цыбульская, О.А. Лобачева, Т.П. Ветлугина, Н.А. Бохан. Заявл. 07.12.2016. Опубл. 08.02.2018. Бюл. № 4.

41. Патент 2613111 Российская Федерация. Способ прогнозирования течения невротических, связанных со стрессом расстройств / В.Б. Никитина, Т.П. Ветлугина, В.А. Рудницкий, О.Э. Перчаткина, В.Ф. Лебедева, Н.А. Бохан. Заявл. 16.11.2015. Опубл. 15.03.2017. Бюл. № 8.

42. Патент 2578966 Российская Федерация. Способ прогнозирования течения соматоформных расстройств / В.Б. Никитина, Т.П. Ветлугина, А.К. Костин, О.Э. Перчаткина, О.А. Лобачева, Д.Н. Савочкина, В.А. Рудницкий, М.М. Аксенов, Н.А. Бохан. Заявл. 20.04.2015. Опубл. 27.03.2016. Бюл. № 9.

43. Мосолов С.Н. Современная антипсихотическая фармакотерапия шизофрении. Русский медицинский журнал. 2004; 12 (10): 646-652.

44. Семке А.В., Ветлугина Т.П., Иванова С.А., Рахмазова Л.Д., Корнетова Е.Г., Федоренко О.Ю., Лобачева О.А. Биологические и клинико-социальные механизмы развития эндогенных психических заболеваний. Сибирский вестник психиатрии и наркологии. 2011; 4 (67): 19-23.

45. Tandon R. Antipsychotics in the treatment of schizophrenia: an overview. J. Clin. Psychiatry. 2011; 72 (1): 4-8. doi: 10.4088/JCP.10075su 1.01

46. Горобец Л.Н. Нейроэндокринные дисфункции и нейролептическая терапия. М.: ИД Медпрактика-М, 2007: 312.

47. Горобец Л.Н., Узбеков М.Г. Динамика уровней пролактина, эстрадиола и тестостерона у женщин с шизоаффективным расстройством при терапии атипичными антипсихотиками. Российский медико-биологический вестник им. акад. И.П. Павлова. 2008; 3: 71-78.

48. Юнилайнен О.А., Старостина Е.Г., Дзеранова Л.К., Колесникова Г.С. Гончаров Н.П., Рытик Э.Г., Кудряшкина Г.Н., Тулинцева Е.Н., Кессельман Л.Г., Баранов П.А., Дедов И.И. Эпидемиологические характеристики гиперпролактинемии, ассоциированной с приемом нейролептиков. Современная терапия в психиатрии и неврологии. 2014; 4: 12-23.

49. Aia P.G., Revuelta G.J., Cloud L.J., Factor S.A. Tardive Dyskinesia. Current Treatment Options in Neurology Published online. 2011. URL: http:// www.springerlink.com/content/q3756t767p17600r (дата обращения 02.03.2011)

50. Цыганков Б.Д., Агасарян Э.Г. Анализ эффективности и безопасности современных и классических антипсихотических препаратов. Журн. неврологии и психиатрии им. С.С. Корсакова. 2010; 110 (9): 64-70

51. Северин Е.С. Биохимические основы патологических процессов. Учебное пособие. М.: Медицина, 2000: 304.

52. Kolov S.A. Levels of plasma serum dehydroepiandrosteronesulfate and cortisol in combat veterans. Eur. Psychiatry. 2010; 25 (1): 960.

53. Peeters B.W. Tonnaer J.A., Groen M.B. Glucocorticoid receptor antagonists: new tools to investigate disorders characterized by cortisol hypersecretion. Stress. 2004; 7 (4): 233-241.

54. Di Dalmazi G., Vicennati V., Rinaldi E. et al. Progressively increased patterns of subclinical cortisol hypersecretion in adrenal incidentalomas differently predict major metabolic and cardiovascular outcomes: a large cross-sectional study. Eur $J$ Endocrinol. 2012; 166(4): 669-677.

55. Ветлугина Т.П., Матафонова Е.В., Бохан Н.А., Никитина В.Б., Мандель А.И., Лобачева О.А. Параметры иммунитета и уровень кортизола у больных опийной наркоманией при синдроме отмены. Патологическая физиология и экспериментальная терапия. 2017; 61 (3): 38-45.

56. Газиева И.А., Чистякова Г.Н., Ремизова И.И., Тарасова М.Н. Спонтанная и митогениндуцированная продукция цитокинов в ранние сроки беременности в зависимости от ее исходов. Иммунология. 2013; 34 (4): 193-198.

57. Прокопьева В.Д., Мандель А.И., Ярыгина Е.Г. Персонализированная антиоксидантная терапия при алкогольной зависимости. Наркология. 2017; 16 (6): 31-35.

58. Бохан Н.А., Иванова С.А. Окислительный стресс при алкоголизме: возможности метаболической коррекции на этапе формирования ремиссии. Наркология. 2010; 9 ; 10 (106): 4549.

59. Ceni E., Mello T., Galli A. Pathogenesis of alcoholic liver disease: Role of oxidative metabolism. World J Gastroenterol. 2014; 20(47): 17756-17772. doi: 10.3748/wjg.v20.i47.17756

60. Palmisano M., Pandey S.C. Epigenetic mechanisms of alcoholism and stress-related disorders. Alcohol. 2017; 60: 7-18. doi: 10.1016/j.alcohol.2017.01.001

61. Ветлугина Т.П., Никитина В.Б., Лобачева О.А., Мандель А.И., Ляшенко Г.П., Рощина О.В. Уровень кортизола и тестостерона у больных алкоголизмом при синдроме отмены. Сибирский вестник психиатрии и наркологии. 2017; 3 (96): 5-10. doi: 10.26617/1810-3111-2017-3(96)-5-10

Поступила в редакцию 2.02.2018 Утверждена к печати 2.04.2018

Никитина Валентина Борисовна, д.м.н., заведующая лабораторией клинической психонейроиммунологии и нейробиологии.

Лобачева Ольга Анатольевна, д.м.н., в.н.с. лаборатории клинической психонейроиммунологии и нейробиологии.

Ветлугина Тамара Парфеновна, д.б.н., профессор, заслуженный деятель науки РФ, в.н.с. лаборатории клинической психонейроиммунологии и нейробиологии, руководитель отдела биологической психиатрии и наркологии.

Аксенов Михаил Михайлович, д.м.н., профессор, заведующий отделением пограничных состояний.

Лебедева Валентина Федоровна, д.м.н., заслуженный врач РФ, главный врач клиники.

Никитина Валентина Борисовна, valentina08@sibmail.com 
For citation: Nikitina V.B., Lobacheva O.A, Vetlugina T.P., Axenov M.M, Lebedeva V.F. Neuroimmunoendocrine dysfunctions in mental disorders and addictions. Siberian Herald of Psychiatry and Addiction Psychiatry. 2018; 2 (99): 45-55. https://doi.org/10.26617/1810-3111-2018-2(99)-44-55

\section{Neuroimmunoendocrine dysfunctions in mental disorders and addictions Nikitina V.B., Lobacheva O.A, Vetlugina T.P., Axenov M.M, Lebedeva V.F.}

Mental Health Research Institute, Tomsk National Research Medical Center, Russian Academy of Sciences Aleutskaya Street 4, 634014, Tomsk, Russian Federation

\section{ABSTRACT}

The study of pathogenetic mechanisms of mental disorders and addictions with use of complex clinical-biological approach is one of the tasks of basic research within scientific platform 'Psychiatry and addictions". Objective: to investigate participation of the immune and endocrine systems in clinical-dynamic mechanisms of mental disorders and addictions. Material and Methods: A complex clinical-immunoendocrine examination of 149 patients with non-psychotic mental disorders, 65 schizophrenic patients, 136 patients with drug addiction and 18 males with alcohol dependence is carried out. The phenotyping of immunocompetent cells according to clusters of differentiation by method of flow cytometry, identification of concentrations of serum immunoglobulins of classes M, G, and A and the level of hormones by the method of IEA; identification of concentration of cytokines on multiplex analyzer MAGPIX according to Luminex xMAP Technology (USA); identification of phagocytic activity of neutrophils in the test with melamine - formaldehyde latex is performed. Results: Data are obtained that give evidence of participation of the immunoendocrine system in the formation of psychopathological disorders and their polymorphism in non-psychotic mental disorders with dominance of anxiety and depressive symptoms. Based on immunological approach methods of prediction of protracted course of neurotic, stress-related and somatoform disorders are developed. Deviations in the system of neuroimmunoendocrine regulation are a common pathogenetic mechanism of development of endogenous disorders. Data on features of action of the atypical neuroleptic risperidone in the process of the therapy in the main parameters of the immunity of schizophrenic patients respective from presence or absence of medicinal hyperprolactinemia are obtained. Deregulation of parameters of the immunoendocrine system in addictions is established at all studied stages of withdrawal syndrome that gives evidence of instability of achieved therapeutic remission, necessity of carrying out the further rehabilitative activities, development of approaches to new algorithms of treatment and rehabilitation of patients for the purpose of stabilization of remissions and prevention of early relapses.

Keywords: clinical psychoneuroimmunology, immunity, cytokines, hormones, non-psychotic mental disorders, schizophrenia, alcoholism, drug addiction.

\section{REFERENCES}

1. Axenov M.M., Stoyanova I.Ya., Tsybulskaya E.V., Kostin A.K Psihologicheskie osobennosti patsientov pozhilogo vozrasta s nepsihoticheskimi psihicheskimi rasstroystvami [Psychological traits of aged patients with non-psychotic mental disorders]. Vestnik Tomskogo gosudarstvennogo pedagogicheskogo universiteta - Tomsk State Pedagogical University Bulletin. 2015; 3 (156): 58-63 (in Russian).

2. Bokhan N.A., Gychev A.V., Rakhmazova L.D., Vasilieva N.A. Rasprostranennost nepsihoticheskih psihicheskih rasstroystv $\mathrm{v}$ Sibirskom federalnom okruge: vzaimosvyaz s regionalnyimi sotsialno-ekonomicheskimi trendami razvitiya [Prevalence of nonpsychotic mental disorders in the Siberian Federal Region: relation to regional socioeconomic development trends]. Sotsialnaya $i$ klinicheskaya psihiatriya - Social and Clinical Psychiatry. 2015; 25 (2): 78-82 (in Russian).

3. Kolmogorova V.V. Tipologiya, sotsialno-demograficheskie i kliniko-psihologicheskie harakteristiki pri formirovanii nepsihoticheskih nervno-psihicheskih rasstroystva [Typology, socialdemographic and clinical-psychological characteristics during formation of non-psychotic neuropsychiatric disorders]. Nauchnyie issledovaniya: ot teorii k praktike - Scientific Studies: From Theory to Practice. 2016; 4-1 (10): 83-86 (in Russian).

4. Sekirina T.P., Omelchenko M.A., Rumyantsev A.O. Issledovanie produktsii pro- i protivovospalitelnyih tsitokinov pri nepsihoticheskih rasstroystvah yunosheskogo vozrasta [Study of production of pro- and anti-inflammatory cytokines in nonpsychotic disorders at adolescent age]. Psihiatriya - Psychiatry. 2015; 1 (65): 24-28 (in Russian).

5. Nikitina V.B. Rol immunnyih mehanizmov $\mathrm{v}$ klinicheskoy dinamike posttravmaticheskih stressovyih rasstroystva [Role of immune mechanisms in clinical course of posttraumatic stress disorders]. Sibirskiy vestnik psihiatrii $i$ narkologii - Siberian Herald of Psychiatry and Addiction Psychiatry. 2009; 3 (54): 14-16 (in Russian).

6. Ivanova S.A. Psihoemotsionalnyiy stress i immunitet (obzor) [Psychoemotional stress and immunity (review)]. Sibirskiy vest- nik psihiatrii i narkologii - Siberian Herald of Psychiatry and Addiction Psychiatry. 2000; 1: 31-37 (in Russian).

7. Lobacheva O.A. Sravnitelnaya otsenka immunomoduliruyuschih effektov atipichnyih neyroleptikov [Comparative characteristic of immunomodulatory effects of atypical neuroleptics. Sibirskiy vestnik psihiatrii $i$ narkologii - Siberian Herald of Psychiatry and Addiction Psychiatry. 2011; 1 (64): 100-102 (in Russian).

8. Vetlugina T.P., Nevidimova T.I., Semke V.Ya. Klinicheskaya psihoneyroimmunologiya [Clinical Psychoneuroimmunology]. In: Aktualnyie problemyi neyroimmunopatologii. Rukovodstvo [Relevant problems of neuroimmunopathology. Handbook]. G.N. Kryzhanovsky, S.N. Magaeva, S.G. Morozov, eds. M.: Publishing House "Genius Media", 2012; Chapter 7: 316-354 (in Russian).

9. Müller N., Wagner J.K., Krause D., Weidinger E., Wildenauer A., Obermeier M., Dehning S., Gruber R., Schwarz M.J. Impaired monocyte activation in schizophrenia. Psychiatry. 2012; 198 (3): 341-346. doi: 10.1016/j.psychres.2011.12.049

10. Girgis R.R., Kumar S.S., Brown A.S. The cytokine model of schizophrenia: emerging therapeutic strategies. Biol. Psychiatry. 2014; 75 (4): 292-299. doi: 10.1016/j.biopsych.2013.12.002

11. Muller N., Schwarz M. Schizophrenia as an inflammationmediated dysbalance of glutamatergic neurotransmission. $\mathrm{Neu}$ rotox Res. 2006; 10 (2):131-48.

12. Bokhan N.A., Ivanova S.A., Levchuk L.A. Serotoninovaya sistema $\mathrm{v}$ modulyatsii depressivnogo $\mathrm{i}$ addiktivnogo povedeniya [Serotonin system in modulation of depressive and addictive behavior]. Tomsk: Publishing House of Tomsk University, 2013: 102 (in Russian).

13. Volkow N.D., Koob G.F., McLellan A.T. Neurobiological Advances from the Brain Disease Model of Addiction. N. Engl. J. Med. 2016; 374 (4): 363-71. doi: 10.1056/NEJMra1511480

14. Devoyno L.V., Idova G.V., Alperina E.L Psihoneyroimmunomodulyatsiya: povedenie i immunitet. Rol «neyromediatornoy ustanovki mozga» [Psychoneuroimmunomodulation: behavior and immunity. Role of the neuromediator aim of the brain]. Novosibirsk: Nauka, 2009: 168 (in Russian). 
15. Kryzhanovsky G.N., Akmaev I.G., Magaeva S.V., Morozov S.G. Neyroimmunoendokrinnyie vzaimodeystviya $\mathrm{v}$ norme patologii [Neuroimmunoendocrine interactions in norm and pathology]. Moscow: Meditsinskaya kniga, 2010: 288 (in Russian).

16. Markova E.V. Mehanizmyi neyroimmunnyih vzaimodeystviy v realizatsii povedencheskih reaktsiy [Mechanisms of neuroimmune interactions in realization of behavioral reactions]. Krasnoyarsk: Nauchno-innovatsionnyiy tsentr, 2012: 236 (in Russian).

17. Ader R., Cohen N., Felten D. Psychoneuroimmunology: interactions between the nervous system and the immune system. Lancet. 1995; 345 (8942): 99-103.

18. Devoino L., Cheido M, Alperina E., Idova G. Evidence for a role of dopaminergic mechanisms in the immunostimulating effect of $\mu$ opioid receptor agonist DAGO. International Journal of Neuroscience. 2003; 113 (10): 1381-1394. doi:10.1080/00207450390231437

19. McGorry P., Keshavan M., Goldstone S., Amminger P., Allot K., Berk M., Lavoie S., Pantelis C., Yung A., Wood S., Hickie I. Biomarkers and clinical staging in psychiatry. World Psychiatry. 2014; 13 (13): 211-223.

20. Kubasov R.V. Gormonalnyie izmeneniya v otvet na ekstremalnyie faktoryi vneshney sredyi [Hormonal changes in response to extreme environment factors]. Vestnik Rossiyskoy akademii meditsinskih nauk - Bulletin of Russian Academy of Medical Sciences. 2014; 9-10: 102-109 (in Russian).

21. Shushpanova T.V., Novozheeva T.P., Mandel A.I., Bokhan N.A. Benzodiazepinovyie retseptoryi trombotsitov i neyroaktivnyie steroidnyie gormonyi v krovi cheloveka - potentsialnyie misheni pri alkogolnoy addiktsii [Benzodiazepine receptors of thrombocytes and neuroactive steroid hormones in human blood - potential targets in alcohol addiction]. Akademicheskiy zhurnal Zapadnoy Sibiri - Academic Journal of West Siberia. 2014; 3 (52): 73-75 (in Russian).

22. Ranabir S., Reetu K. Stress and hormones. Indian J Endocrinol Metab. 2011; 1: 18-22. doi: 10.4103/2230-8210.77573

23. Babb J.A., Carini L.M., Spears S.L., Nephew B.C. Transgenerational effects of social stress on social behavior, corticosterone, oxytocin, and prolactin in rats. Horm Behav. 2014; 4: 386-393. doi: 10.1016/j.yhbeh.2014.03.005

24. Gamaleya N.B. Narusheniya funktsiy immunnoy sistemyi pri alkogolnoy i narkoticheskoy zavisimosti [Dysfunctions of the immune system in alcohol and drug dependence]. In: Narkologiya. Natsionalnoe rukovodstvo [Narcology. National Handbook]. N.N. Ivanets N.N., I.P. Anokhina, M.A. Vinnikova, eds. Moscow: GEOTAR-Media; 2008: 116-134 (in Russian).

25. Anokhina I.P. Osnovnyie biologicheskie mehanizmyi zavisimosti ot psihoaktivnyih veschestv [Main biological mechanisms of substanc dependence]. Voprosyi narkologii - Journal of Addiction problems. 2013; 6: 40-59 (in Russian).

26. Chang M.C., Fan S.Z., Hsiao P.N., Cheng W.F., Sun W.Z. Influence of morphine on host immunity. Acta Anaesthesiol. Taiwan. 2011; 49 (3): 105-108. doi: 10.1016/j.aat.2011.08.003

27. Crews F.T., Vetreno R.P. Neuroimmune basis of alcoholic brain damage. Int Rev Neurobiol. 2014; 118: 315-57. doi: 10.1016/B978-0-12-801284-0.00010-5

28. Panchenko L.F., Pirozhkov S.V., Naumova T.A., Terebilina N.N., Baronets V.Yu., Fedorov I.G., Totolyan G.G. Izmenenie profilya vospalitelnyih i protivovospalitelnyih tsitokinov pri razvitii alkogolnoy bolezni pecheni [Change of profile of inflammatory and pro-inflammatory cytokines during development of liver alcohol disease]. Narkologiya - Narcology. 2010; 4 (100): 86-77 (in Russian)

29. Afshar M., Richards S., Mann D., Cross A., Smith G.B., Netzer G., Kovacs E., Hasday J. Acute immunomodulatory effects of binge alcohol ingestion. Alcohol. 2015; 49 (1): 57-64. doi: 10.1016/j.alcohol.2014.10.002

30. Manzardo A.M., Poje A.B., Penick E.C., Butler M.G. Multiplex Immunoassay of Plasma Cytokine Levels in Men with Alcoholism and the Relationship to Psychiatric Assessments. Int $\mathrm{J} \mathrm{Mol}$ Sci. 2016; 17 (4): 472. doi: 10.3390/ijms17040472

31. McEwen B.S. Physiology and neurobiology of stress and adaptation: central role of the brain. Physiol Rev. 2007; 3: 873-904. doi:10.1152/physrev.00041.2006

32. Charney D.S. Psychobiological mechanisms of resilience and vulnerability: implications for successful adaptation to extreme stress. Am. J. Psychiatry. 2004; 161 (2): 195-216. doi: 10.1176/appi.ajp.161.2.195.

33. Kolomachenko V.I., Krivobok V.I., Fesenko V.S. Передопераційна та післяопераційна тривожність в ортопедичних пацієнтів: кореляція з біохімічними стрес-маркерами [Preand postsurgical anxiety in orthopedic pateints: correlation with biochemical stress-markers]. Український вісник психоневрологї - Ukrainian Bulletin of Psychoneurology. 2010; 2 (63): 52-56 (in Ukrainian). .

34. Lennartsson A.K., Jonsdottir I.H. Prolactin in response to acute psychosocial stress in healthy men and women. Psychoneuroendocrinology. 2011; $36 \quad$ (10): 1530-1539. doi: 10.1016/j.psyneuen.2011.04.007

35. Labad J., Stojanovic-Pérez A., Montalvo I., Solé M. Stress biomarkers as predictors of transition to psychosis in at-risk mental states: roles for cortisol, prolactin and albumin. J Psychiatr Res. 2015; 60: 163-169. doi: 10.1016/j.jpsychires.2014.10.011

36. Heimer L., Van Hoesen G.W. The limbic lobe and its output channels: implications for emotional functions and adaptive behavior. Neurosci. Biobehav. Rev. 2006; 30 (2): 126-147. doi: 10.1016/j.neubiorev.2005.06.006

37. Matarese G., Procaccini C., Menale C., Kim J.G., Kim J.D., Diano S., Diano N., De Rosa V., Dietrich M.O., Horvath T.L. Hunger-promoting hypothalamic neurons modulate effector and regulatory T-cell responses. Proc Natl Acad Sci USA. 2013; 110 (15): 6193-6198. doi: 10.1073/pnas.1210644110

38. Christensen R., Van Ameringen M., Hall G. Increased activity of frontal and limbic regions to emotional stimuli in children at-risk for anxiety disorders. Psychiatry Res. 2015; Jul 30; 233 (1): 917. doi: 10.1016/j.pscychresns.2015.04.004

39. Vetlugina T.P., Nevidimova T.I., Nikitina V.B., Lobacheva O.A., Bokhan N.A., Semke V.Ya. Patogeneticheskoe obosnovanie tehnologii immunokorrektsii pri psihicheskih rasstroystvah i boleznyah zavisimosti [Pathogenetic background of technology of immunocorrection in mental disorders and dependence illnesses]. Sibirskiy vestnik psihiatrii $i$ narkologii - Siberian Herald of Psychiatry and Addiction Psychiatry. 2013; 1 (76): 7-12 (in Russian).

40. Patent 2644309 Russian Federation. Sposob prognozirovaniya riska formirovaniya panicheskogo rasstroystva na ranney stadii zabolevaniya [Method of prediction of formation of panic disorder at different stages of the diseae]. V.B. Nikitina, T.V. Kazennykh, A.A. Ivanova, E.V. Tsyibulskaya, O.A. Lobacheva, T. P.Vetlugina, N. A. Bokhan. Applied 07.12.2016. Published 08.02.2018. Bull. no. 4 (in Russian).

41. Patent 2613111 Russian Federation. Sposob prognozirovaniya techeniya nevroticheskih, svyazannyih so stressom rasstroystv [Method of prediction of the course of neurotic, stress-related disorders]. V.B. Nikitina, T.P. Vetlugina, V.A. Rudnitsky, O.E. Perchatkina, V.F. Lebedeva, N.A. Bokhan. Applied 16.11.2015. Published 15.03.2017. Bull. no. 8 (in Russian).

42. Patent 2578966 Russian Federation. Sposob prognozirovaniya techeniya somatoformnyih rasstroystv [Method of prediction of the course of somatoform disorders]. V.B. Nikitina, T.P. Vetlugina, A.K. Kostin, O.E. Perchatkina, O.A. Lobacheva, D.N. Savochkina, V.A. Rudnitsky, M.M. Axenov, N.A. Bokhan. Applied 20.04.2015. Published 27.03.2016. Bull. no. 9 (in Russian).

43. Mosolov S.N. Sovremennaya antipsihoticheskaya farmakoterapiya shizofrenii [Current antipsychotic pharmacotherapy of schizophrenia]. Russkiy meditsinskiy zhurnal - Russian Medical Journal. 2004; 12 (10): 646-652 (in Russian).

44. Semke A.V., Vetlugina T.P., Ivanova S.A., Rakhmazova L.D., Kornetova E.G., Fedorenko O.Yu., Lobacheva O.A. Biologicheskie i kliniko-sotsialnyie mehanizmyi razvitiya endogennyih psihicheskih zabolevaniy [Biological and clinical-social mechanisms of endogenous mental diseases development]. Sibirskiy vestnik psihiatrii $i$ narkologii- Siberian Herald of Psychiatry and Addiction Psychiatry. 2011; 4 (67): 19-23 (in Russian).

45. Tandon R. Antipsychotics in the treatment of schizophrenia: an overview. J. Clin. Psychiatry. 2011; 72 (1): 4-8. doi: 10.4088/JCP.10075su 1.01

46. Gorobets L.N. Neyroendokrinnyie disfunktsii i neyrolepticheskaya terapiya [Neuroendocrine dysfunctions and neuroleptic therapy]. M.: ID Medpraktika-M, 2007: 312 (in Russian). 
47. Gorobets L.N., Uzbekov M.G. Dinamika urovney prolaktina, estradiola i testosterona $\mathrm{u}$ zhenschin s shizoaffektivnyim rasstroystvom pri terapii atipichnyimi antipsihotikami [Dynamics of the levels of prolactin, estradiol and testosterone in women with schizophrenia and schizoaffective disorders during the therapy using atypical antipsychotic drugs]. Rossiyskiy mediko-biologicheskiy vestn. im. akad. I.P. Pavlova - I.P. Pavlov Russian Medico-Biological Bulletin. 2008; 3: 71-78 (in Russian).

48. Yunilainen O.A., Starostina E.G., Dzeranova L.K., Kolesnikova G.S. Goncharov N.P., Rytik E.G., Kudryashkina G.N., Tulintseva E.N., Kesselman L.G., Baranov P.A., Dedov I.I. Epidemiologicheskie harakteristiki giperprolaktinemii, assotsiirovannoy s priemom neyroleptikov [Epidemiological characteristics of antipsychotic-induced hyperprolactinemia]. Sovremennaya terapiya $v$ psihiatrii $i$ nevrologii - Current Therapy in Psychiatry and Neurology. 2014; 4: 12-23 (in Russian).

49. Aia P.G., Revuelta G.J., Cloud L.J., Factor S.A. Tardive Dyskinesia Current Treatment Options in Neurology Published online. 2011. URL: http:// www.springerlink.com/content/q3756t767p17600r (дата обращения 02.03.2011)

50. Tsygankov B.D., Agasaryan E.G. Analiz effektivnosti i bezopasnosti sovremennyih i klassicheskih antipsihoticheskih preparatov [Epidemiological characteristics of antipsychoticinduced hyperprolactinemia]. Zhurnal nevrologii i psihiatrii im. S.S. Korsakova - S.S. Korsakov Journal of Neurology and Psychiatry. 2010; 110 (9): 64-70 (in Russian).

51. Severin E.S. Biohimicheskie osnovyi patologicheskih protsessov. Uchebnoe posobie [Biochemical bases of pathological processes. Tutorial]. Moscow: Meditsina, 2000: 304 (in Russian).

52. Kolov S.A. Levels of plasma serum dehydroepiandrosteronesulfate and cortisol in combat veterans. Eur. Psychiatry. 2010; 25 (1): 960

53. Peeters B.W. Tonnaer J.A., Groen M.B. Glucocorticoid receptor antagonists: new tools to investigate disorders characterized by cortisol hypersecretion. Stress. 2004; 7 (4): 233-241.

54. Di Dalmazi G., Vicennati V., Rinaldi E. et al. Progressively increased patterns of subclinical cortisol hypersecretion in adrenal incidentalomas differently predict major metabolic and cardiovascular outcomes: a large cross-sectional study. Eur $J$ Endocrinol. 2012; 166 (4): 669-677.

55. Vetlugina T.P., Matafonova E.V., Bohan N.A., Nikitina V.B., Mandel A.I., Lobacheva O.A. Parametryi immuniteta i uroven kortizola u bolnyih opiynoy narkomaniey pri sindrome otmenyi [Immune parameters and level of cortisol in patients with opiate addiction during withdrawal syndrome]. Patologicheskaya fiziologiya i ekspermentalnaya terapiya - Pathological Physiology and Experimental Therapy. 2017; 61 (3): 38-45 (in Russian).

56. Gazieva I.A., Chistyakova G.N., Remizova I.I., Tarasova M.N Spontannaya i mitogenindutsirovannaya produktsiya tsitokinov $\mathrm{v}$ rannie sroki beremennosti $\mathrm{v}$ zavisimosti ot ee ishodov [Spontaneous and mitogen-induced production of cytokines in early terms of pregnancy respective from its outcomes]. Immunologiya - Immunology. 2013; 34 (4): 193-198 (in Russian).

57. Prokopieva V.D., Mandel A.I., Yarygina E.G. Personalizirovannaya antioksidantnaya terapiya pri alkogolnoy zavisimosti [Personalized antioxidant therapy in alcohol dependence]. Narkologiya - Narcology. 2017; 16 (6): 31-35 (in Russian).

58. Bokhan N.A., Ivanova S.A. Okislitel'nyy stress pri alkogolizme: vozmozhnosti metabolicheskoy korrektsii na etape formirovaniya remissii [Oxidative stress in alcoholism: opportunities of metabolic correction on the stage of remission's formation]. Narkologiya - Narcology. 2010; 9; 10 (106): 45-49 (in Russian).

59. Ceni E., Mello T., Galli A. Pathogenesis of alcoholic liver disease: Role of oxidative metabolism. World J Gastroenterol. 2014; 20 (47): 17756-17772. doi: 10.3748/wjg.v20.i47.17756

60. Palmisano M., Pandey S.C. Epigenetic mechanisms of alcoholism and stress-related disorders. Alcohol. 2017; 60: 7-18. doi: 10.1016/j.alcohol.2017.01.001

61. Vetlugina T.P., Nikitina V.B., Lobacheva O.A., Mandel A.I., Lyashenko G.P., Roshchina O.V. Uroven kortizola i testosterona u bolnyih alkogolizmom pri sindrome otmenyi [Cortisol and testosterone levels in alcoholic patients in withdrawal syndrome]. Sibirskiy vestnik psihiatrii i narkologii - Siberian Herald of Psychiatry and Addiction Psychiatry. 2017; 3 (96): 5-10. doi: 10.26617/1810-3111-2017-3(96)-5-10 (in Russian).

Received February 2.2018 Accepted April 2.2018

Nikitina Valentina B., MD, Head of the Laboratory of Clinical Psychoneuroimmunology and Neurobiology, Mental Health Research Institute, Tomsk National Research Medical Center, Russian Academy of Sciences, Tomsk, Russian Federation.

Lobacheva Olga A., MD, lead researcher of the Laboratory of Clinical Psychoneuroimmunology and Neurobiology, Mental Health Research Institute, Tomsk National Research Medical Center, Russian Academy of Sciences, Tomsk, Russian Federation.

Vetlugina Tamara P., ScD., Prof., lead researcher of the Laboratory of Clinical Psychoneuroimmunology and Neurobiology, Mental Health Research Institute, Tomsk National Research Medical Center, Russian Academy of Sciences, Tomsk, Russian Federation.

Axenov Mikhail M., MD, Prof., Head of Borderline States Department, Mental Health Research Institute, Tomsk National Research Medical Center, Russian Academy of Sciences, Tomsk, Russian Federation.

Lebedeva Valentina F., MD, chief physician of clinic, Mental Health Research Institute, Tomsk National Research Medical Center, Russian Academy of Sciences, Tomsk, Russian Federation.

$\triangle$ Nikitina Valentina B., valentina08@sibmail.com 